\title{
Erratum to: Impact of Thermal Treatment on Physicochemical, Antioxidative and Rheological Properties of White-Flesh and Red-Flesh Dragon Fruit (Hylocereus spp.) Purees
}

Wijitra Liaotrakoon • Nathalie De Clercq

Vera Van Hoed • Davy Van de Walle • Benny Lewille •

Koen Dewettinck

Published online: 16 February 2013

(C) Springer Science+Business Media New York 2013

Erratum to: Food Bioprocess Technol (2013) 6:416-430

$$
\text { DOI 10.1007/s11947-011-0722-4 }
$$

The original version of the article unfortunately contained a mistake. The unit of DPPH value present in Fig. 5 (a.3 and b.3) and Fig. 6 (c) is incorrect. Kindly see below the correct graphs:

Fig. 5 (a.3)

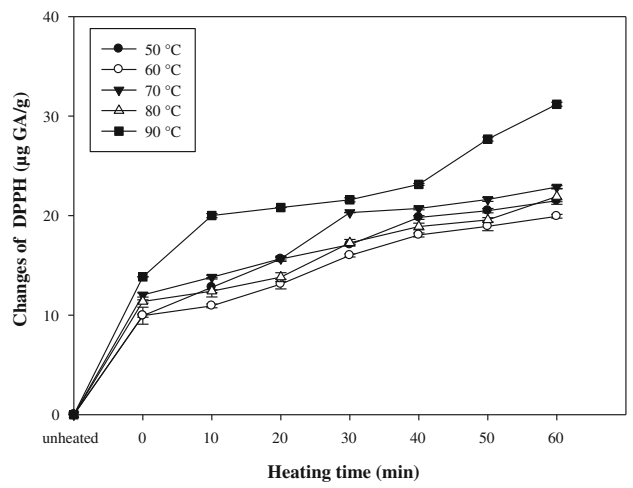

The online version of the original article can be found at http://dx.doi.org/ 10.1007/s11947-011-0722-4.

W. Liaotrakoon $(\bowtie) \cdot$ N. De Clercq $\cdot$ D. Van de Walle

B. Lewille $\cdot K$. Dewettinck

Laboratory of Food Technology and Engineering,

Department of Food Safety and Food Quality,

Faculty of Bioscience Engineering, Ghent University,

9000 Ghent, Belgium

e-mail: wijitra.liaotrakoon@ugent.be

\section{Van Hoed}

Department of Sustainable Organic Chemistry and Technology,

Faculty of Bioscience Engineering, Ghent University,

9000 Ghent, Belgium
Fig. 5 (b.3)

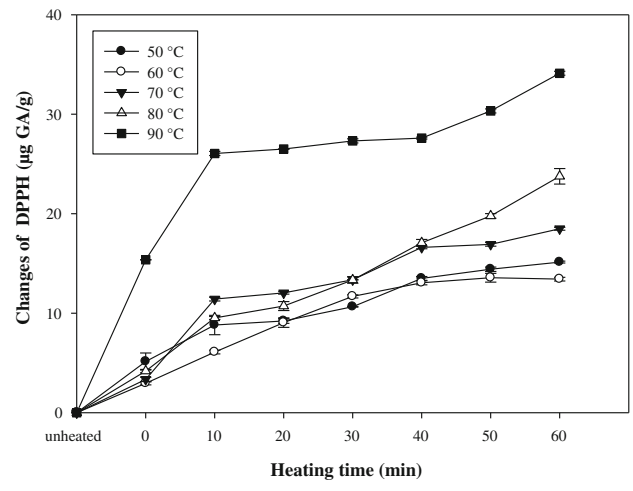

Fig. 6 (c)

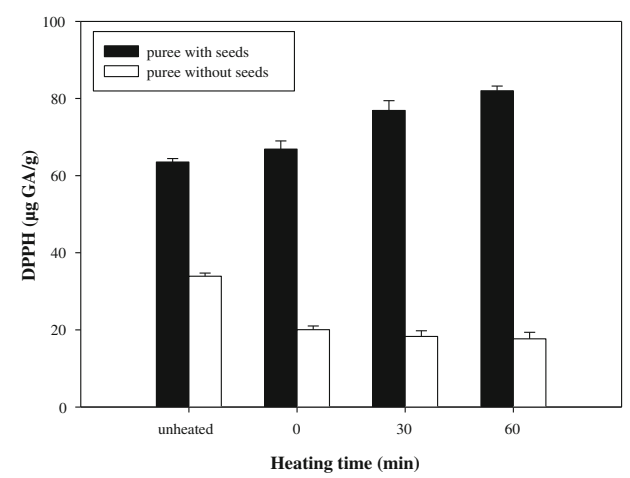

